\title{
II \\ EL NUEVO REGLAMENTO DEL CONGRESO DE LOS DIPUTADOS
}

Al elaborar esta Crónica Parlamentaria relativa al actual Reglamento del Congreso de los Diputados (de 10 de febrero de 1982) hemos querido señalar todos aquellos puntos novedosos que nos ofrece respecto del Reglamento Provisional (de 13 de octubre de 1977), así como todas las innovaciones que han sido recogidas en su seno como consecuencia del mandato constitucional. Esta Crónica no es un estudio exhaustivo ni tampoco un análisis crítico del nuevo Reglamento del Congreso; se trata tan sólo de una visión particular de todos los aspectos relevantes que, a nuestro juicio, merecen ser destacados.

En el fondo, como todas las cosas, el actual Reglamento del Congreso de los Diputados es producto de unas circunstancias determinadas y de un tiempo histórico. En esas circunstancias y en ese tiempo hemos de considerarlo al realizar su análisis y al emitir un juicio de valor sobre él. ¡Nada más interesante que profundizar en el contexto histórico en el cual se llevó a cabo. el proceso de gestación del Reglamento!... Pero ésa es otra historia y debe ser contada en otra parte.

\section{ACTIVIDAD LEGISLATIVA}

\section{Procedimiento legislativo ordinario}

\section{A) Proyectos de ley}

a) Presentación de enmiendas. En la redacción del artículo 94.2 del anterior Reglamento, las enmiendas a la totalidad, además de versar sobre la oportunidad, los principios o el espíritu del proyecto, podían proponer la devolución de éste 0 bien propugnar una nueva redacción del texto. Ahora, el nuevo Reglamento del Congreso, en su artículo 110.3, establece que las enmiendas a la totalidad son las que versan sobre la oportunidad, los principios o el espíritu del proyecto de ley y postulen la devolución de aquél al Gobierno o las que propongan un texto completo alternativo al del proyecto.

b) Deliberación en la Comisión. El artículo 113 del nuevo Reglamento, en su punto primero, admite la posibilidad de que, finalizado el debate de totalidad, si lo hubiere habido, y en todo caso, el plazo de presentación de enmiendas, la Comisión nombre en su seno uno o varios ponentes que, a la vista del texto y de las enmiendas presentadas al articulado, redacte un informe en el plazo de quince días.

Es conveniente señalar también que, a pesar de que el artículo 6.1 del Reglamento sólo reconoce expresamente a los diputados el derecho de asistir con voto, sin mencionar que también con voz, a las sesiones de las Comisiones, el artículo 114.1 RCD dispone curiosamente que una vez concluido el informe de la Ponencia comenzará el debate en Comisión, que se hará artículo por artículo, pudiendo hacer uso de la palabra los enmendantes al artículo y los miembros de la Comisión. En este caso, los diputados hacen uso de su no reglamentado derecho a la palabra 
como diputados individuales miembros de una Comisión y no como representantes de un Grupo Parlamentario.

En lo que respecta a la dirección de los debates de la Comisión, puede decirse que el presidente de ésta, de acuerdo con la Mesa, puede llegar a cercenar dichos debates, ya que el punto dos del artículo 115 le permite establecer el tiempo máximo de la discusión para cada artículo y el que corresponde a cada intervención.

c) Deliberación en el Pleno. E1 significativo aumento de los poderes de la Presidencia con respecto al Reglamento Provisional es notorio en los puntos $2 .^{\circ}$ y $3 .^{\circ}$ del artículo 118 del Reglamento actual, los cuales disponen que la Presidencia de la Cámara, oídas la Mesa y la Junta de Portavoces, podrá:

1. Ordenar los debates y las votaciones por artículos, o bien, por materias, grupos de artículos o de enmiendas, cuando lo aconseje la complejidad del texto, la homogeneidad o interconexión de las pretensiones de las enmiendas o la mayor claridad en la confrontación política de las posiciones.

2. Fijar de antemano el tiempo máximo de debate de un proyecto, distribuyéndolo, en consecuencia, entre las intervenciones previstas y procediéndose, unz vez agotado, a las votaciones que quedaren pendientes.

\section{B) Proposiciones de ley}

Destacar el artículo 127 del nuevo Reglamento referido a las proposiciones dt. ley de las Comunidades Autónomas y las de iniciativa popular, que constituye una norma más elaborada por imperativo constitucional.

\section{Procedimiento de reforma constitucional}

Es ésta otra sección del nuevo Reglamento redactada por imperativo de la Constitución para regular el procedimiento a travếs del cual se deben tramitar los proyectos y proposiciones de reforma constitucional a que se refieren los artículos 166 y 167 del texto constitucional. Según lo dispuesto por el Reglamento (art. 146.1), dichos proyectos y proposiciones de reforma constitucional se tramitarán conforme a las normas establecidas en él para los proyectos y proposiciones de ley (arts. 108 a $129 \mathrm{RCD}$ ), si bien éstas deben ir suscritas por dos Grupos Parlamentarios o por una quinta parte de los diputados, lo cual supone una traba importante a la adopción de una iniciativa parlamentaria para reformar la Constitución. ( $\mathrm{El}$ art. 126.1 RCD permite que las proposiciones de ley sean adoptadas a iniciativa de un diputado, con la firma de otros catorce miembros de la Cámara, o de un Grupo Parlamentario, con la sola firma de su portavoz.)

\section{Procedimiento en lectura única}

Conforme a lo establecido en el punto primero del artículo 150 del Reglamento, el Pleno de la Cámara, a propuesta de la Mesa y oída la Junta de Portavoces, podrá acordar que un proyecto o proposición de ley se tramiten directamente y en lectura única cuando la naturaleza de éstos lo aconseje o su simplicidad de formulación lo permita. Una vez que se adopta tal acuerdo por el Pleno del Congreso, se procede al debate que está sujeto, según dispone el artículo 150.2, a las normas establecidas para el de totalidad. 
La tramitación de un proyecto de ley en lectura única es una innovación del Reglamento actual que se puso en marcha por vez primera con el Convenio Hispano-Norteamericano.

\section{Tratados y convenios internacionales}

En primer lugar podríamos señalar que en el artículo $154 \mathrm{RCD}$ está ya presente la idea, largamente acariciada por los Gobiernos españoles, de que nuestro país sea pronto miembro de pleno derecho de las Comunidades Europeas, al disponer que la celebración de Tratados por los que se atribuya a una organización o institución internacionales el ejercicio de competencias derivadas de la Constitución requerirá la previa autorización de las Cortes mediante ley orgánica.

También es importante dejar constancia de la remisión que el artículo 156.1 $\mathrm{RCD}$ hace al procedimiento legislativo común para la tramitación en el Congreso de la concesión de autorizaciones de tratados internacionales.

Por otra parte, y como ya venía dispuesto en el anterior Reglamento (si bien menos explícitamente), las propuestas presentadas por los diputados y Grupos Parlamentarios que pretendan la denegación o el aplazamiento de la autorización solicitada o propusieran reservas o declaraciones y éstas no estuvieran previstas por el Tratado o Convenio, tendrán la consideración de enmiendas a la totalidad (art. 156.2 RCD). Por el contrario, se tramitarán como enmiendas al articulado aquellas propuestas presentadas por los diputados o Grupos Parlamentarios que propusieran la supresión, adición o modificación a las reservas o declaraciones que el Gobierno pretendiera formular, o que formularen reservas o declaraciones previstas por el Tratado o Convenio (art. 156.3 RCD).

Frente al silencio que guardaba el anterior Reglamento, las discrepancias Congreso-Senado sobre la concesión de autorización para celebrar Tratados o Convenios previstos en el artículo 94.1 de la Constitución vienen reguladas en el artículo 158 del Reglamento actual.

\section{ACTIVIDAD FINANCIERA \\ 1. Materia presupuestaria}

Destacar que, al igual que el anterior Reglamento (art. 106.2), el actual establece, en su artículo 133, que el Proyecto de Ley de Presupuestos Generales del Estado gozará de preferencia en la tramitación con respecto a los demás trabajos parlamentarios.

Por otra parte, y a tenor de lo dispuesto en el punto cuarto del citado artículo, todas aquellas enmiendas al Proyecto de Ley de Presupuestos que supongan minoración de ingresos requerirán la conformidad del Gobierno para su tramitación. A la vista de este precepto, podríamos preguntarnos si la intromisión que supone esta exigencia de conformidad gubernamental es o no contraria a lo establecido por el artículo 134.5 de la Constitución, y según el cual sólo después de aprobados los Presupuestos Generales del Estado podrá el Gobierno presentar proyectos de ley que impliquen aumento del gasto público o disminución de los ingresos correspondientes al mismo ejercicio presupuestario. 


\section{Materia tributaria}

Según lo establecido en el apartado séptimo del artículo 134 del texto constitucional, la Ley de Presupuestos no puede crear tributos y sólo podrá modificarlos cuando una ley tributaria sustantiva así lo prevea. Entendemos que la iniciativa para elaborar esa ley puede partir del Gobierno o de un Grupo Parlamentario siempre y cuando cuente con la anuencia del Gobierno. El debate de esa ley tributaria se ajustará a lo dispuesto para los de totalidad.

\section{Ordenación general o singular de la economia}

La Constitución de 1978 reconoce expresamente en su artículo 128.2 la iniciativa pública en la actividad económica. La reserva al sector público de recursos o servicios esenciales y la intervención de empresas cuando así lo exigiere el interés general se hará mediante ley.

Los proyectos de ley cuya finalidad sea la ordenación singular de la economía se tramitarán conforme al procedimiento legislativo común.

También podemos señalar como especialidad en este tema el control de los informes del Tribunal de Cuentas que, a tenor del artículo $199 \mathrm{RCD}$, deben ser remitidos anualmente al Congreso de los Diputados.

\section{ACTIVIDAD DE CONTROL DEL CONGRESO SOBRE EL GOBIERNO}

\section{Actos de control con eficacia juridica}

\section{A) Investidura (arts. 170 a $172 \mathrm{RCD}$ )}

Es éste un capítulo nuevo, redactado en cumplimiento de las previsiones establecidas en el artículo 99 de la Constitución. Las disposiciones del nuevo Reglamento referidas a este tema difieren sustancialmente de las de la «Resolución de la Presidencia sobre regulación parlamentaria de la votación de investidura» de 29 de marzo de 1979 (BOC de 29 marzo 1979). Según esta citada resolución, el debate acerca del programa expuesto por el candidato a presidente de Gobierno debía efectuarse con posterioridad a la votación que otorga o deniega la confianza, mientras que, a tenor de lo dispuesto en el actual Reglamento, el debate debe desarrollarse con anterioridad a dicha votación.

Podemos recordar que la investidura del hoy presidente del Gobierno Felipe González se llevó a cabo según lo preceptuado por el Reglamento actual.

\section{B) Cuestión de confianza (arts. 173 y 174 RCD)}

En la redacción de este nuevo capítulo se ha tenido muy en cuenta la experiencia de la Legislatura pasada, en la que el presidente Suárez solicitó de la Cámara Baja su confianza en septiembre de 1980, así como las disposiciones establecidas en «la Resolución de la Presidencia sobre presentación y votación de la cuestión de confianza» de 15 de septiembre de 1980 (BOC de 19 de septiembre de 1980). 
C) Moción de censura (arts. 175 a $179 \mathrm{RCD}$ )

En lo que respecta a la regulación actual de la moción de censura, hay que decir que coincide esencialmente con la «Resolución de la Presidencia sobre las normas del procedimiento a seguir en el debate y votación de la moción de censura» de 28 de mayo de 1980 (BOC de 6 de junio de 1980).

\section{D) Control sobre disposiciones del Gobierno con fuerza de ley}

Una importante innovación introducida por este Reglamento viene dada por el hecho de que el debate y votación sobre la convalidación o derogación de un Real Decreto-ley se realizará en el Pleno de la Cámara o de la Diputación Permanante antes de transcurrir los treinta días siguientes a su promulgación, conforme a lo dispuesto en el artículo 86.2 de la Constitución, es decir, por imperativo constitucional y no por acuerdo de la Junta de Portavoces.

Otra nota a resaltar es la del artículo 151.5 del Reglamento, según la cual la Diputación Permanente podrá, en su caso, tramitar como proyectos de ley, por el procedimiento de urgencia, los Decretos-leyes que el Gobierno dicte durante los períodos entre legislaturas. ¿Significa esto que la Diputación Permanente tiene potestad para tramitar iniciativas legislativas?

\section{E) Referéndum consultivo (art. $161 \mathrm{RCD}$ )}

En desarrollo del artículo 92 de la Constitución, el artículo 161 del nuevo Reglamento dispone la forma en que deberá producirse la necesaria autorización previa del Congreso parra que el referéndum pueda celebrarse. Según lo preceptuado reglamentariamente, el debate a que será sometido el mensaje o comunicación que a esos efectos dirija el presidente del Gobierno al Pleno de la Cámara Baja se ajustará a las normas previstas para el debate de totalidad.

\section{F) Estados de anomalia en la vida del Estado (art. 162 a 165 RCD)}

Es éste también un nuevo capítulo del Reglamento redactado por exigencias constitucionales de desarrollo procedimental del artículo 116.

\section{G) La acusación a miembros del Gobierno por delitos de traición o contra la seguridad del Estado (art. 169 RCD)}

El artículo 169 del Reglamento del Congreso encuentra su fundamento en el artículo 102 de la Constitución relativo a la responsabilidad criminal del presidente y demás miembros del Gobierno. Siguiendo lo ya establecido en el precepto constitucional, la norma reglamentaria dispone que la iniciativa para plantear dicha responsabilidad criminal por traición o delitos contra la seguridad del Estado corresponde a un número de diputados no inferior a la cuarta parte de los miembros del Congreso. El debate del Pleno en sesión secreta se ajustará a las normas previstas para los de totalidad, si bien el diputado afectado podrá hacer uso de la palabra en cualquier momento. La votación debe ser secreta por papeletas. 


\section{Actos de control sin eficacia jurídica}

\section{A) Proposiciones no de ley}

Ninguna novedad a reseñar con respecto al Reglamento provisional de 1977 (arts. 193 a $195 \mathrm{RCD}$ ).

\section{B) Interpelaciones}

En este capítulo referente a las interpelaciones que los diputados y los Grupos Parlamentarios pueden formular al Gobierno podemos destacar las facultades calificadoras de la Mesa del Congreso (art. 181.2 RCD) respecto de los escritos que se le presenten, así como una mejor tipificación de la figura de la interpelación (CFR, art. 125 R. Prov.). Igualmente podemos señalar, por su novedad, el punto segundo del artículo $192 \mathrm{RCD}$, donde se establece la posibilidad de que la Mesa, oída la Junta de Portavoces, declare no admisibles a trámite aquellas interpelaciones cuyo texto profiera palabras o vertiere conceptos ofensivos al decoro de la Cámara o de sus miembros, de las Instituciones del Estado o de cualquier otra persona o entidad.

Innovación es también el establecimiento de una prioridad, para su inclusión en el orden del día, de las interpelaciones de los diputados o de Grupos Parlamentarios que en el correspondiente período de sesiones no hubieren consumido el cupo resultante de asignar una interpelación por cada diez diputados o fracción perteneciente al mismo (art. 182.2 RCD). Por otra parte, también nos resulta novedoso el punto tercero del artículo $182 \mathrm{RCD}$ según el cual finalizado un período de sesiones, las interpelaciones pendientes se tramitarán como preguntas con respuesta por escrito, salvo que el interpelante manifieste expresamente su voluntad de mantener la interpelación para dicho período.

\section{C) Preguntas}

Las preguntas que, a tenor del artículo $185 \mathrm{RCD}$, pueden formular los diputados al Gobierno encuentran en la nueva reglamentación un doble límite, ya que no serán admitidas, según el art. 186.2 RCD:

1..$^{\circ}$ Las preguntas de exclusivo interés personal de quien la formula o de cualquier otra persona singularizada.

2. Las preguntas que supongan consulta de indole estrictamente jurídica.

Por otra parte, frente a la insuficiente regulación del Reglamento Provisional en este tema (respuesta oral ante el Pleno), el artículo 188.2 del actual Reglamento permite al presidente, de acuetdo con la Junta de Portavoces, señalar el número de preguntas a incluir en el orden del día de cada sesión plenaria y distribuirlas entre los diputados correspondientes a cada Grupo Parlamentario. Respecto a la distribución de los tiempos de intervención, el punto tercero del artículo 188 RCD señala que será el presidente y los intervinientes quienes se ocuparán de hacerlo, sin que en ningún caso la tramitación de la pregunta pueda exceder de cinco minutos.

En lo que atañe a las preguntas respecto de las cuales se pretende respuesta oral en Comisión, decir que, a tenor del artículo $189.2 \mathrm{RCD}$ se tramitarán como si fueran preguntas con respuesta oral ante el Pleno, con la particularidad de que 
las primeras intervenciones serán por tiempo de diez minutos y las de réplica de cinco.

Por último, puede decirse que las semanas en que exista sesión ordinaria del Pleno se dedicarán, por regla general, dos horas como tiempo mínimo a preguntas e interpelaciones, lo cual significa que puede haber también sesiones ordinarias del Pleno reservadas para asuntos determinados en las que no haya interpelaciones ni preguntas.

\section{D) Comunicaciones del Gobierno}

El nuevo Reglamento del Congreso regula en sus artículos 196 y 197 el procedimiento a través del cual se debe desarrollar el debate a que dé lugar una comunicación del Gobierno remitida al Congreso de los Diputados. A tenor de lo preceptuado en dichos artículos, la comunicación enviada por el Gobierno puede ser debatida ante el Pleno o en Comisión; el debate se inicia con la intervención de un miembro del Gobierno, tras la cual pueden hacer uso de la palabra los representantes de los Grupos Parlamentarios, por un tiempo máximo de quince minutos y con un derecho a réplica de diez minutos. Una vez finalizado el debate, $y$ en un plazo de treinta minutos, los Grupos Parlamentarios pueden presentar propuestas de resolución que podrán ser defendidas durante cinco minutos como máximo para ser posteriormente votadas.

\section{E) Sesiones informativas del Gobierno}

A tenor de lo dispuesto en el artículo 202 RCD, los miembros del Gobierno comparecerán ante la Comisión correspondiente del Congreso cuando así lo solicite dicha Comisión a a petición propia, para celebrar una sesión informativa. El desarrollo de estas sesiones informativas consta de las siguientes fases:

- Exposición oral del ministro.

- Suspensión de la sesión por un tiempo máximo de cuarenta y cinco minutos para que los diputados y Grupos Parlamentarios puedan preparar la formulación de preguntas u observaciones.

- Contestación de las preguntas u observaciones por el ministro, que podrá ser asistido por autoridades y funcionarios de su departamento.

Asimismo, los miembros del Gobierno, a petición propia, o por acuerdo de la Mesa de la Cámara y de la Junta de Portavoces, deberán comparecer para informar sobre un asunto determinado. La iniciativa para la adopción de tales acuerdos corresponde a dos Grupos Parlamentarios o a la quinta parte de los miembros de la Cámara o de la Comisión (art. 203 RCD). Estas sesiones informativas sobre un asunto determinado constan de las siguientes fases:

- Exposición oral de los miembros del Gobierno.

- Intervención de los representantes de los Grupos Parlamentarios para fijar posiciones, formular preguntas o hacer observaciones. El tiempo máximo para cada Grupo será de diez minutos.

- Contestación de los miembros del Gobierno, sin posterior votación.

Por último; el punto tercero del artículo 203 RCD dispone que, en casos excepcionales, la Presidencia podrá, de acuerdo con la Mesa y oída la Junta de Por: 
tavoces, abrir un turno para que los diputados puedan formular escuetas preguntas o pedir aclaraciones. El número de intervenciones será fijado por el presidente de la Cámara.

\section{ACTIVIDADES DE INTEGRACION DE OTROS ORGANOS POLITICOS}

\section{Por imperativo constitucional}

El Reglamento del Congreso, en su artículo 204, se refiere al procedimiento mediante el cual se proponen y designan los cuatro miembros del Consejo General del Poder Judicial y los cuatro Magistrados del Tribunal Constitucional a que se refieren, respectivamente, los artículos 122.3 y 151.1 de la Constitución. El procedimiento del artículo 204, con la exigencia de una mayoría cualificada de miembros del Congreso de los Diputados (tres quintos de los votos), es seguido, asimismo, para la elección del Defensor del Pueblo.

\section{Por imperativo legal}

El sistema establecido en el citado artículo 204 RCD es también de aplicación a todos aquellos supuestos en los que un precepto legal prevea la propuesta, la aceptación y el nombramiento de personas por una mayoría cualificada de miembros del Congreso. Este es precisamente el caso del nombramiento de los miembros del Consejo de Administración de RTVE (conforme al Estatuto de RTVE de 10 de enero de 1980), del Consejo de Seguridad Nuclear y de los componentes del Tribunal de Cuentas.

\section{ACTIVIDAD DEL CONGRESO RELACIONADA CON LAS COMUNIDADES AUTONOMAS}

\section{Actividad de carácter normativo}

\section{A) Estatutos de Autonomia}

Toda esta sección referente a los Estatutos de Autonomía es totalmente nueva y responde a un imperativo constitucional. En ella se regula:

1. El procedimiento ordinario referido a la tramitación del proyecto de Estatuto elaborado conforme al procedimiento previsto en los artículos 143, 144 y 146 y Disp. trans. primera de la Constitución (art. 136 RCD).

2. ${ }^{\circ}$ El procedimiento referido al proyecto de Estatuto elaborado conforme al procedimiento previsto en el artículo 151 de la Constitución (art. 134 a 144 RCD).

3. La reforma de los Estatutos de Autonomía que, de acuerdo con el artículo $145 \mathrm{RCD}$, requerirá aprobación mediante ley orgánica.

\section{B) Leyes de armonización}

En virtud de lo dispuesto en el artículo 150.3 de la Constitución referente a la potestad del Estado para dictar leyes que establezcan los principios necesarios 
para armonizar las disposiciones normativas de las Comunidades Autónomas cuando así lo exija el interés general, dispone el artículo 168.1 del Reglamento que la apreciación de esa necesidad de dictar leyes de armonización deberá ser acordada por la mayoría absoluta del Congreso en un debate sujeto a las normas de los de totalidad.

\section{Actividad de carácter no normativo}

\section{A) Autorizaciones de los acuerdos entre Comunidades Autónomas}

Conforme al artículo $166 \mathrm{RCD}$, los acuerdos entre Comunidades Autónomas para la gestión y prestación de servicios públicos de las mismas serán remitidos por la Mesa a la Comisión Constitucional a los efectos previstos en los correspondientes Estatutos de Autonomía. Por otra parte, en los casos en que se reciba una comunicación del Senado que autorice o deniegue la autorización para celebrar un acuerdo de cooperación entre Comunidades Autónomas que no esté referido a los supuestos citados anteriormente, la Mesa la remitirá a la Comisión Constitucional para que emita un dictamen que será discutido en el Pleno conforme al procedimiento establecido respecto a los debates de totalidad. Si el acuerdo del Congreso fuera coincidente con el del Senado, el presidente de aquél lo pondrá en conocimiento de los presidentes de las Comunidades afectadas. Si fuera contrario, se lo comunicará al presidente del Senado para proceder al nombramiento de la Comisión Mixta prevista en el artículo 74.2 de la Constitución, la cual deberá presentar un texto que será sometido a votación de ambas Cámaras. Si no llegara a ser aprobado de esta forma, decidirá el Congreso por mayoría absoluta.

\section{ORGANIZACION INTERNA DEL CONGRESO}

El nuevo Reglamento del Congreso presenta numerosas novedades en materia de auto-organización de la Cámara, que bajo diferentes epígrafes se tratan de exponer ordenadamente a continuación.

\section{Estatuto de los Diputados}

Cabe destacar, en primer lugar, el hecho de que el Reglamento sólo reconoce a los diputados de manera expresa el derecho de asistir con voto, pero sin mencionar que también con voz, a las sesiones del Pleno del Congreso y a las de las Comisiones de que formen parte (art. $60^{\circ}, 1$ ). El no reconocimiento expreso del derecho de todo diputado a opinar pone de relieve la fuerza con que vienen imponiéndose los Grupos Parlamentarios como protagonistas de la actividad de las Cámaras, a la vez que hace pensar en el riesgo de que quede arrasada la condición del diputado individual como representante por sí mismo de la nación. Si bien la Constitución consagra el mandato representativo cuando prohíbe el imperativo entre diputados (representantes) y electores (representados), el precepto reglamentario citado se muestra proclive a establecer un nuevo tipo de mandato imperativo: el que liga al diputado con su Grupo Parlamentario o partido político. De esta forma, puede negarse al diputado su derecho a hablar en el Parlamento, lo que podría comprometer la naturaleza misma de la Cámara parlamentaria como foro de deliberación política entre los representantes de la nación. Aquí incumbe un im- 
portante papel a los órganos de gobierno de la Cámata en el sentido de interpretar con carácter extensivo cuantas normas permitan la intervención de diputados individuales, lo cual es especialmente factible por lo que se refiere a las deliberaciones de las Comisiones, concibiéndolas no como órganos con pretendidas competencias propias, sino como órganos parlamentarios de pura preparación de los trabajos del Pleno de la Cámara.

Por otra parte, el artículo 16 del Reglamento provisional facultaba a los diputados, para el mejor cumplimiento de sus funciones, a recabar información de la Administración pública a través de la Presidencia del Congreso. El Reglamento vigente introduce una importante novedad en su artículo $7 .^{\circ}, 1$, al posibilitar que los diputados puedan recabar de todas las Administraciones públicas la información que obre en poder de éstas (Comunidades Autónomas, Diputaciones, Ayuntamientos e incluso Administraciones de carácter institucional), y no sólo de la Administración Central del Estado. La medida es coherente con el principio de unidad del Estado que, en función de la soberanía, expresa la Constitución, así como con la nueva distribución tertitorial del poder que la misma Constitución consagra.

De otro lado, y de acuerdo con el principio de generalidad y de igualdad contributiva, el nuevo Reglamento establece que todas las percepciones de los diputados se hallan sujetas a las normas tributarias de carácter general (art. $8 .^{\circ}, 3$ ), lo que supone una innovación respecto del inicio de la Legislatura constituyente, pudiendo serlo también a estos efectos respecto del principio de la condición de irretenibles de las asignaciones económicas de los diputados, sobre el que guarda silencio el Reglamento presente, a diferencia de lo establecido en el artículo 19 del Reglamento provisional.

En materia de inmunidad parlamentaria, se lleva la Institución más allá de lo que resultaba del anterior Reglamento. En efecto, frente al silencio positivo, esto es, favorable a la concesión de la autorización para proceder judicialmente contra un diputado, una vez transcurrido el plazo que la Cámara tenía para pronunciarse, se establece ahora (art. 14.2) la técnica del silencio negativo, de modo que se entenderá denegada la autorización si en el plazo de sesenta días naturales el Congreso no se hubiera pronunciado. De acuerdo con el principio, que la doctrina comparte generalmente en la actualidad, de que la inmunidad parlamentaria ya no se justifica en nuestro tiempo, una interpretación restrictiva de la inmunidad parece hubiera resultado más conforme con el Estado de Derecho de nuestros días.

El artículo 19.3, por su parte, establece un plazo máximo de ocho días para que el diputado incurso en incompatibilidad pueda optar entre el escaño y el cargo incompatible. Es ésta una norma completa e interesante que evita el supuesto de indecisión de un diputado incurso en compatibilización de funciones incompatibles, si bien el sistema de incompatibilidades existente tampoco se ajusta a la realidad actual.

Se ha de resaltar también otra innovación del Reglamento referida a la adquisición plena de la condición de diputado en base al cumplimiento de una serie de requisitos, entre los cuales destaca el de prestar promesa o juramento de acatar la Constitución (art. 20.1.3. ). Se preceptúa asimismo que, si bien los derechos y prerrogativas serán efectivos desde el momento mismo en que el diputado es proclamado electo, carecerá de los mismos en el supuesto de que se celebraran tres sesiones plenarias sin que el diputado adquiera la condición plena de tal, por no haber cumplido el requisito anterior (art. 20.2).

En cuanto a la pérdida de la condición de diputado, materia lamentablemente desatendida por el Reglamento provisional con consecuencias deplorables, el artículo 22 del nuevo Reglamento parece señalar taxativamente las causas, cuando en realidad incurre en defecto de técnica normativa al olvidar la causa establecida en 
el artículo 19.3, referente al diputado incurso en incompatibilidad que no ejercite su opción entre el escaño y el cargo incompatible en el plazo de ocho días, con lo que se entiende que renuncia al escaño.

\section{Constitución del Congreso}

La primera novedad que nos ofrece el nuevo Reglamento está referida a su sesión constitutiva. Frente al derecho parlamentario histórico español, en el que hasta llegar a la constitución definitiva de la Cámara misma y de su principal órgano de gobierno, que es la Mesa, las sesiones se celebraban sólo para tratar de verificación de actas y de asuntos excepcionales, pero siempre con carácter provisional; frente a ello, los artículos $2 .^{\circ}$ y $3 .^{\circ}$ del actual Reglamento disponen que la sesión constitutiva será presidida inicialmente por la Mesa de edad (formada por el diputado electo de mayor edad de los presentes, asistido por los dos más jóvenes en calidad de secretarios), para proceder en esa misma sesión a la elección de Ia Mesa definitiva del Congreso. Ello obedece a dos razones básicas. La primera se refiere a la mayor rapidez en el cómputo de los sufragios emitidos en las elecciones, como consecuencia de la utilización de avances técnicos e informáticos que agilizan sobremanera el proceso y permiten emitir en breve espacio de tiempo credenciales de las Actas obtenidas por los respectivos diputados electos. La otra razón, de carácter histórico, acaso tiene que ver con la forma en que se produjo la sesión de investidura como primer presidente constitucional, en mayo de 1979; del presidente Suárez. En aquel momento, conforme al Reglamento provisional del Congreso, la Mesa de la Cámara tenía también carácter provisional y su presidente era presidente interino. El procedimiento de investidura, regulado en el artículo 99 de la Constitución, carecía de desarrollo en el Reglamento provisional de la Cámara, por lo que correspondía al presidente del Congreso, de acuerdo con el artículo 23 in fine del propio Reglamento provisional, interpretar éste o suplirlo en los casos de duda u omisión. El entonces candidato a la Presidencia del Gobierno mantuvo al parecer el criterio de que la sesión de investidura debía comenzar por la presentación del programa de Gobierno que se proponía formar, continuar por la votación a fin de otorgarle o denegarle la confianza de la Cámara para formar Gobierno y terminar con la deliberación acerca del programa de gobierno presentado; entendía, pues, que la deliberación tenía que ser posterior a la votación de investidura, con lo que comprometía las facultades de interpretación del Reglamento por la Presidencia de la Cámara. Para evitar situaciones semejantes y garantizar la independencia del presidente de la Cámara, el Reglamento actual elimina tanto la Junta Preparatoria de Diputados electos como la fase provisional de actuación de la Cámara y de la Mesa provisional, imponiendo la constitución definitiva de la Mesa, comprendida la elección de su presidente por mayoría absoluta, en la primera sesión del Congreso (art. 37.1).

\section{Mesa del Congreso}

Las funciones que corresponden a la Mesa del Congreso vienen señaladas en el artículo 31 del actual Reglamento. De ellas podemos destacar como novedosas las siguientes:

a) La de elaborar el proyecto de presupuesto del Congreso de los Diputados, dirigir y controlar su ejecución y presentar ante el Pleno de la Cámara, al final de cada ejercicio, un informe acerca de su cumplimiento (art. 31.1.2. $)$.

b) La de calificar, con arreglo al Reglamento, los escritos y documentos de 
índole parlamentaria, así como declarar la admisibilidad o inadmisibilidad a trámite de los mismos (art. 31.1.4. ${ }^{\circ}$. Esta función de la Mesa es una facultad parlamentaria de gobierno de la Cámara, que ya aparecía recogida genéricamente en el Reglamento provisional (art. 22), pero no tan clara y rotundamente como ahora.

c) La de programar las líneas generales de actuación de la Cámara, fijar el calendario de actividades del Pleno y de las Comisiones para cada período de sesiones y coordinar los trabajos de sus distintos órganos, todo ello previa audiencia de la Junta de Portavoces (art. 31.1.6..$^{\circ}$.

Asimismo resulta innovador el hecho de haber conferido legitimación activa a todo diputado o Grupo Parlamentario para recurrir contra las decisiones adoptadas por la Mesa en el ejercicio de sus funciones, a que se refieren los puntos $4 .^{\circ}$ y 5. del apartado primero del artículo 31 (calificación, admisión y tramitación de todos los escritos y documentos de índole parlamentaria). Al final, la Mesa decide, oída la Junta de Portavoces, mediante resolución motivada.

\section{Sesión solemne de apertura de la Legislatura}

Otra innovación del Reglamento es la consignada en su artículo $5 .^{\circ}$, cuando establece que, en el plazo de los quince días siguientes a la celebración de la sesión constitutiva del Congreso, tendrá lugar la solemne sesión de apertura de la legislatura por S. M. el Rey, con lo que se viene a corroborar un uso que se inició el 21 de julio de 1977, para la que llegó a ser Legislatura constituyente, y se reiteró en mayo de 1979, pasando así de costumbre parlamentaria a la categoría de norma parlamentaria escrita.

\section{Grupos Parlamentarios}

Tanto el Reglamento provisional como el definitivo establecen la regla general de que los diputados, en número no inferior a 15 , podrán constituirse en Grupo Parlamentario. Este número se redujo a 5 el 3 de mayo de 1979, de modo que el Partido Socialista Andaluz pudo formar en la primera Legislatura su propio Grupo Andalucista. Sin embargo, frente al Reglamento provisional, que posibilitaba a formación de Grupos Parlamentarios a los diputados miembros de aquellas formaciones políticas que hubieran concurrido como tales a las elecciones y obtenido, al menos, un 20 por 100 de los escaños en el conjunto de las circunscripciones en que hubieran presentado candidaturas, el artículo 23.1 del actual Reglamento sólo permite constituirse en Grupo Parlamentario a los diputados de una o varias formaciones políticas que, aun sin reunir el mínimo de 15 diputados, hubieran obtenido un número de escaños no inferior a 5 y, al menos, el 15 por 100 de los votos correspondientes a las circunscripciones en que hubieran presentado candidatura o el 5 por 100 de los emitidos en el conjunto de la nación. Así pues, conforme a lo prescrito en este artículo 23.1, el Reglamento permite la existencia de Grupos Parlamentarios de ámbito territorial limitado, si bien es claro que sus componentes son representantes de la Nación española.

Con respecto a los diputados que no sean miembros de ninguno de los Grupos Parlamentarios constituidos, señala el nuevo Reglamento que podrán asociarse a alguno de ellos mediante solicitud que, aceptada por el portavoz del Grupo a que pretende asociarse, se dirige a la Mesa en un determinado plazo de tiempo. Esta es la figura de los «asociados», conocida en el Derecho parlamentario francés como los apparentés, y que recibían en el Reglamento provisional la denominación de «adheridos». Ningún diputado ha hecho hasta ahora uso de esta posibilidad, acaso 
porque en el Grupo Mixto posee mayor libertad de voz y de voto de la que tendría en otro grupo como adberido.

Por otra parte, la reducción de un Grupo Parlamentario, durante el transcurso de la Legislatura, a un número inferior a la mitad del mínimo exigido para su constitución, supone, de acuerdo con el artículo 27.2 del Reglamento, su desaparición por disolución, y sus miembros pasarán automáticamente a formar parte del Grupo Mixto. Está claro, pues, que la estructura esencial de la Cámara Baja es inmodificable hasta que el Parlamento llega al término de su mandato o es disuelto, con la excepción de que desaparezca algún Grupo Parlamentario. De esta forma, queda imposibilitada la formación de Grupos Parlamentarios durante la Legislatura.

Es también una novedad digna de reseñarse la consignada en el artículo 28.2 del Reglamento al establecer la obligación para los Grupos Parlamentarios de llevar una contabilidad específica de la subvención asignada por el Congreso, contabilidad que pondrán a disposición de la Mesa siempre que ésta lo pida.

\section{Junta de Portavoces}

Conforme al Reglamento provisional del Congreso (art. 27), el presidente debía reunir regularmente, y siempre que lo estimara conveniente, o a petición de la mitad más uno de los Grupos Parlamentarios, a la Junta de Portavoces, mientras que el actual Reglamento elimina el carácter de periodicidad y establece que ia convocatoria de la Junta de Portavoces podrá hacerse:

- A iniciativa propia del presidente del Congreso.

- A petición de dos Grupos Parlamentarios.

- A petición de la quinta parte de los miembros de la Cámara.

Así pues, la regla general de que la Junta de Portavoces siempre debe ser oída ha sido sustituida por lo establecido en el artículo 39.1 del nuevo Reglamento, que señala tan sólo que aquélla podrá ser oída. La Junta conserva, no obstante, lo esencial de su poder: fijar el orden del día o asuntos a tratar en cada sesión plenaria, de acuerdo con la Presidencia. Esta circunstancia impone la celebración de frecuentes reuniones de la Junta.

\section{Comisiones}

E1 nuevo Reglamento del Congreso parece reconocer, en su artículo 43.1, competencia propia a las Comisiones («Las Comisiones conocerán de los proyectos, proposiciones o asuntos que les encomiende, de acuerdo con su respectiva competencia, la Mesa del Congreso»). Esta atribución genérica de competencia a las Comisiones es criticable, ya que no existe más competencia que la del Congreso, y sólo en el caso de que una ley atribuya específicamente competencia propia a una Comisión puede hablarse de la competencia de ésta (por ejemplo, la Comisión de Radiotelevisión tiene competencia genérica atribuida por el Estatuto de Radiotelevisión de 10 de enero de 1980); aun esta medida podría considerarse inconstitucional si se entiende que modifica el régimen de relación entre las Cortes y el Gobierno de nuestro sistema parlamentario. En los demás casos, las Comisiones gozan de una competencia específica, para cada asunto que somete a dictamen la Mesa de la Cámara (cfr. art. 150).

En cuanto a las Comisiones permanentes (que no son sólo las legislativas), puede señalarse que el Reglamento ha operado una drástica reducción en su nú- 
mero. Anteriormente había tantas Comisiones permanentes como departamentos ministeriales, mientras que en la actualidad han quedado limitadas a once. También desaparecen la Comisión de Corrección de Estilo y la de Gobierno Interior. Se refunden en la Comisión de Estatuto de los Diputados la Comisión de Incompatibilidades y la de Suplicatorios. Por otra parte, y a título de curiosidad, puede decirse que la Comisión de Reglamento (art. 47) es la más numerosa, y asimismo puede destacarse la singular composición de las Comisiones del Estatuto de los Diputados y de Peticiones, que cuentan con un miembro por cada Grupo Parlamentario.

Se mantiene el criterio de que la composición de las Comisiones sea reflejo del espectro de las fuerzas políticas representadas en la Cámara, puesto que el número de los miembros de la Comisión ha de ser proporcional a la importancia numérica de los Grupos Parlamentarios (art. 40.1). Si se tiene en cuenta que se introduce el voto ponderado en el funcionamiento de las Comisiones (art. 88.2), se tendrá conciencia del giro copernicano que se ha operado en la naturaleza de éstas respecto del Derecho histórico. En efecto, el sistema continental de Comisiones en el siglo xIx hacía de éstas un órgano técnico, caracterizado por la competencia de los comisionados en la materia sometida a dictamen, de modo que el parecer expresado era un parecer de expertos que buscaba la convergencia entre competencia y decisión política o democracia. Ahora, de lege lata, todo el proceso de deliberación parlamentaria, desde la Ponencia al Pleno, es político en su integridad.

Por otra parte, caba resaltar, respecto a las Comisiones no permanentes, que, a tenor de lo dispuesto en el artículo 5.1 del nuevo Reglamento, se extinguen a la finalización del trabajo encomendado y, en todo caso, al concluir la Legislatura. Creemos que hubiera sido más adecuado establecer un tiempo límite de duración más corto que el de la Legislatura, tal y como ocurre en el Derecho parlamentario francés, según el cual las Comisiones no permanentes se extinguen en un plazo máximo de seis meses.

Según el artículo 52 del Reglamento, las Comisiones de Investigación son Comisiones no permanentes, y respecto de ellas podemos señalar que pueden ser creadas no sólo a propuesta de la Mesa del Congreso, de dos Grupos Parlamentarios o de la quinta parte de los miembros de la Cámara, sino también del propio poder ejecutivo, del Gobierno (art. $52.1 \mathrm{RCD}$ ). La idea de que sea el propio Gobienno quien pueda pedir el control de la Cámara respecto de su actuación nos parece especialmente favorecedora de un régimen de colaboración de poderes.

Además de las Comisiones de Investigación son también Comisiones no permanentes las llamadas Comisiones de Estudio, que aparecen definidas de forma negativa en el artículo 53 del actual Reglamento como aquellas Comisiones no permanentes distintas de las Comisiones de Investigación. Un ejemplo de estas Comisiones de Estudio es la Comisión de Arrendamientos Urbanos.

\section{Pleno}

Frente al Reglamento provisional del Congreso, según el cual el Pleno era convocado por el presidente de acuerdo con la Mesa (art. 46.1), el actual Reglamento confiere al presidente la facultad de convocar el Pleno sin previo acuerdo de la Mesa, por propia iniciativa o a solicitud, al menos, de dos Grupos Parlamentarios o de una quinta parte de los miembros de la Cámara (art. 54 RCD). 


\section{Medios personales y materiales del Congreso}

La previsión de dotación de medios personales y materiales, que el artículo 60.2 del nuevo Reglamento hace respecto de la Comisión de Presupuestos, puede predicarse de todas las Comisiones.

\section{Sesiones}

Las sesiones, según lo establecido en el artículo 62.1 del Reglamento, se deben celebrar en días comprendidos entre el martes y el viernes, ambos inclusive, de cada semana. Sin embargo, podrán celebrarse en días diferentes de los señalados por acuerdo tomado en Pleno o en Comisión, o por acuerdo de la Mesa del Congreso; siempre y cuando sea aceptado por la Junta de Portavoces (art. 62.2 RCD). Esta exigencia de contar con la aceptación de la Junta de Portavoces supone una importante novedad, que señala la necesidad de la concurrencia de voluntades de los órganos de gobierno de la Cámara.

Pot otra parte, el nuevo Reglamento establece, en su artículo 64, que las sesiones de las Comisiones no serán públicas, si bien podrán asistir los representantes de los medios de comunicación social debidamente acreditados, salvo cuando aquéllas tengan carácter secreto. Conforme al artículo 64, puntos 2 y 3, las sesiones de las Comisiones serán secretas cuando así lo acuerden por mayoría absoluta de sus miembros, y, en todo caso, serán secretas las sesiones y trabajos de la Comisión del Estatuto de los Diputados y de las Comisiones de Investigación. Así, a tenor del art. 99.1.2 $\mathrm{RCD}$, cuando un diputado quebranta el deber.de guardar secreto de las deliberaciones llevadas a cabo en estas Comisiones, cuyas sesiones tienen carácter secreto, puede ser privado, por acuerdo de la Mesa, de alguno o de todos los derechos que le conceden los artículos $60^{\circ}$ a $9 .^{\circ}$ del Reglamento (derecho a asistit con voto a las sesiones del Pleno y de las Comisiones; derecho a formar parte de una Comisión facultad de recabar de las Administraciones públicas los datos $\mathrm{e}$ informes que obren en su poder, derecho a una remuneración y al abono de las cotizaciones de la Seguridad Social, siempre que, como consecuencia de su dedicación parlamentaria, hubiere dejado de prestar el servicio que motivaba su afiliación o pertenencia a aquélla).

\section{Orden del día}

A1 igual que en el anterior Reglamento, el artículo 67.1 del actual dispone que el orden del día del Pleno será fijado por el presidente; de acuerdo con la Junta de Portavoces.

En este tema podemos señalar dos importantes novedades que aparecen consignadas en los apartados 3 y 4 del artículo 67 del actual Reglamento. Por una parte, la posibilidad de que el Gobierno solicite que en una sesión concreta se incluya un asunto con carácter prioritario, siempre que éste haya cumplido los trámites reglamentarios que le hagan estar en condiciones de ser incluido en el orden del día. Y por otra, también la posibilidad de que la Junta de Portavoces, a iniciativa de un Grupo Parlamentario o del Gobierno, acuerde, por razones de urgencia y unanimidad, la inclusión en el orden del día de un determinado asunto, aunque no hubiere cumplido todavía los trámites reglamentarios. 


\section{Los debates}

Según el Diccionario de la Real Academia de la Lengua Española, debate «es la controversia sobre una cosa entre dos o más personas. Es una discusión». Pues bien, después de examinar este capítulo del Reglamento referente a los debates, se llega a la conclusión de que más que la reglamentación de controversias en el seno de la Cámara Baja, se trata de una regulación de monólogos sucesivos. Veamos por qué. En primer lugar, y conforme a lo dispuesto en el artículo 69, ningún debate podrá comenzar sin la previa distribución a todos los diputados con derecho a participar en el Pleno o en la Comisión, al menos con 48 horas de antelación, del informe, dictamen o documentación que haya de servir de base en el mismo, salvo que la Mesa del Congreso o de la Comisión acuerde otra cosa, si bien ese acuerdo en contrario debe estar debidamente justificado. Este inciso final de la posibilidad de acuerdo en contrario de la Mesa del Congreso o de la Comisión es innovación introducida por el nuevo Reglamento.

Por otra parte, cuando el artículo 70.1 RCD establece que «ningún diputado podrá hablar sin haber pedido y obtenido del presidente la palabra», ¿debemos entender que el Reglamento se está refiriendo a un diputado representante de un Grupo Parlamentario? Parecería lógico que así fuera después de haber negado al diputado individual en el artículo 6.1 su derecho a tener voz y no sólo voto.

Por otro lado, el artículo 70.5 del nuevo Reglamento, al igual que el artículo 60 del provisional, señala que los miembros del Gobierno podrán hacer uso de la palabra siempre que lo soliciten; sin embargo, a tenor de lo dispuesto por el Reglamento actual, ello se hará sin perjuicio de las facultades que para la ordenación de los debates corresponden al presidente de la Cámara. Este nuevo párrafo se inscribe en esa línea de reforzamiento de la Presidencia que está presente en todo el actual Reglamento del Congreso, y que se hace asimismo patente en la redacción del artículo 73.2 cuando señala que «lo establecido en el presente Reglamento para cualquier debate se entiende sin perjuicio de las facultades del presidente para ordenar el debate y las votaciones, oída la Junta de Portavoces, y valorando su importancia, ampliar o reducir el número y el tiempo de las intervenciones de los Grupos Parlamentarios o de los diputados, así como acumular, con ponderación de las circunstancias de grupos y materias, todas las que en un dete:minado asunto puedan corresponder a un Grupo Parlamentario». Igualmente, otros preceptos del nuevo Reglamento acentúan e incrementan los poderes del presidente. Así, el artículo 71.3 establece que cuando la alusión de un diputado afecte al decoro o dignidad de un Grupo Parlamentario, el presidente podrá conceder a un representante de aquél el uso de la palabra por un tiempo máximo de tres minutos. Asimismo, y al igual que el artículo $62 \mathrm{del}$ Reglamento provisional, el punto segundo del artículo 72 del nuevo Reglamento otorga al presidente la facultad de denegar, durante el debate, las lecturas que considere no pertinentes o innecesarias.

Es preciso señalar, por la gravedad que puede entrañar poner en peligro la configuración del Parlamento como foro de debate y deliberación, la drástica reducción del tiempo de intervención de los diputados. De esta forma puede comprobarse cómo el artículo 73 RCD limita el tiempo de réplica o rectificación a cinco minutos, señalando además que aquel que fuera contradicho en sus argumentaciones sólo tendrá derecho a replicar o rectificar por una sola vez. Igualmente, frente a los cuarenta y cinco minutos para una intervención en la discusión sobre las líneas generales de un asunto o cuestión y los treinta en relación con cada capítulo o enmienda establecidos en el artículo 64 del Reglamento provisional, el artículo 74.1 del actual tasa el tiempo máximo de intervención en una discusión 
sobre cualquier asunto o cuestión (y salvo precepto en contrario) en diez minutos.

En lo que respecta al Grupo Mixto, el nuevo Reglamento, en su artículo 75, establece la excepción a la regla general enunciada en el artículo 29 según la cual todos los Grupos Parlamentarios gozan de idénticos derechos. E1 Grupo Mixto puede intervenir en los debates a través de un solo diputado y por el mismo tiempo que los demás Grupos, siempre y cuando todos sus componentes presentes así lo acuerden y lo comuniquen a la Presidencia de la Mesa. Si no hubiera tal acuerdo, ningún diputado del Grupo Mixto podrá intervenir en turno de Grupo Parlamentario por más de la tercera parte del tiempo establecido para cada Grupo Parlamentario y sin que puedan intervenir más de tres diputados. Ahora bien, el tiempo será de la mitad, y en lugar de tres diputados serán dos, cuando el tiempo resultante de la división por tres no fuera igual o superior a cinco minutos. Por otra parte, si se produjeran serias discrepancias entre los miembros del Grupo Mixto respecto de quién ha de intervenir, será el presidente quien decida en el acto, y en función de las diferencias reales de posición, pudiendo llegar a denegar la palabra a todos.

Es también novedad lo establecido en el punto cuarto del artículo 75: «Todos los turnos generales de intervención de los Grupos Parlamentarios serán iniciados por el Grupo Parlamentario Mixto.»

Decir, por último, respecto a los debates, que, a través del artículo 76 del nuevo Reglamento, la Presidencia, de acuerdo con la Mesa, puede acordar el cierre de una discusión cuando estimare que un asunto está suficientemente debatido. No es fácil comprender esta facultad del presidente en una Cámara donde el tiempo de intervención está tan limitado y tasado.

\section{Las votaciones}

Como es habitual, el Reglamento actual exige, en su artículo 78.1, la existencia de la mayoría de los miembros de la Cámara para adoptar acuerdos, y si llegado el momento de la votación o celebrada ésta resultase que no existe el quorum, se pospondrá por un plazo máximo de dos horas. Esta exigencia de quorum es normal en todos los Parlamentos; sin embargo, suele ser también normal que aquél se presuma siempre y cuando no se solicite su comprobación.

Por otra parte; frente al artículo 75 del Reglamento provisional («La votación será nominal o secreta en las Comisiones o en el Pleno cuando así lo pidan dos Grupos Parlamentarios o cincuenta diputados en éste, o cuatro diputados en aquélla»), el artículo 85 del actual Reglamento dispone que la votación será pública por llamamiento o secreta cuando así lo exija el propio Reglamento o lo soliciten dos Grupos Parlamentatios o una quinta parte de los diputados o de los miembros de la Comisión, dejando muy claro que en ningún caso la votación podrá ser secreta en los procedimientos legislativos.

Respecto a los casos en que se produjera un empate en alguna votación, tanto el anterior Reglamento como el actual disponen la realización de una segunda votación, y si aquél persistiese, se dejará transcurrir un plazo determinado y se repetirá la votación. Si de nuevo se produjera un empate, se entenderá desechado el dictamen, artículo, enmienda, voto particular o proposición de que se trate (art. 79 del Reglamento provisional y art. 88.1 RCD). Sin embargo, frente al silencio del anterior Reglamento, el actual entiende que no existe empate, en las votaciones en Comisión cuando la igualdad de votos, siendo idéntico el sentido en el que hubieran votado todos los miembros de la Comisión pertenecientes a un mismo Grupo Parlamentario, pudiera dirimirse ponderando el número de votos con que cada Grupo cuente en el Pleno (art. 88.2 RCD). 
En lo que se refiere al tiempo máxima de explicación de voto, una vez verificada la votación, el artículo 89.1 del actual Reglamento lo ha reducido a cinco minutos frente a los diez tasados en el artículo 80 del Reglamento provisional.

\section{Cómputo de los plazos y de la presentación de documentos}

Señalar tan sólo que el nuevo Reglamento establece, en su artículo 90.1, que los plazos señalados por días, salvo que hubiere disposición en contrario, se computarán en días hábiles, cuando lo normal es que se computen en días naturales, dado que el Parlamento no es un departamento ministerial ni un órgano de la Administración pública.

\section{Publicaciones del Congreso y de la publicidad de sus trabajos}

Con el nuevo Reglamento adquieren rango de publicaciones oficiales del Congreso de los diputados el Boletín Oficial de las Cortes Generales, Sección Congreso de los Diputados, y el Diario de Sesiones del Pleno de la Cámara, de la Diputación Permanente y de las Comisiones (art. 95 RCD).

Por otra parte, e igualmente inscrito en el tono general de incremento de los poderes de la Presidencia, el artículo 98.3 RCD dispone que, sin la autorización expresa del presidente del Congreso, nadie podrá realizar grabaciones gráficas o sonoras de los órganos de la Cámara.

\section{Disciplina parlamentaria}

\section{A) Las sanciones por el incumplimiento de los deberes de los diputados}

Constituye una importante novedad de este Reglamento la enumeración de una serie de supuestos por los que un diputado puede verse privado de alguno o de todos los derechos contemplados en los artículos $6 .^{\circ}$ a $90^{\circ}$ del propio Reglamento. Esos supuestos tasados en el artículo 99.1 son los siguientes:

1..$^{\circ}$ Que el diputado dejara de asistir voluntariamente a las sesiones del Pleno o de las Comisiones de forma reiterada o notoria.

2. Que el diputado quebrantare el deber de secreto establecido en el artículo 16 del Reglamento.

Además, las sanciones (cuya extensión y duración son determinadas por la Mesa mediante acuerdo motivado) podrán extenderse a la parte alícuota de la subvención (art. 99.2 RCD).

Mientras que el artículo 85 del Reglamento provisional sólo preveía la suspensión temporal de la condición de diputado en los casos en que el diputado agrediere, intentare agredir o amenazare a otro diputado o a cualquier asistente a la sesión, o con su conducta de obra o de palabra promoviese desorden grave, dificultando la prosecución de la reunión, el nuevo Reglamento amplía las posibilidades de suspender temporalmente a un diputado de su condición de tal, mediante acuerdo del Pleno de la Cámara, a los siguientes supuestos (art. 101.1 $\mathrm{RCD})$ : 
1. Cuando, impuesta y cumplida la sanción prevista en el artículo 99, el diputado persistiera en su actitud.

2. Cuando el diputado portare armas dentro del recinto parlamentario.

3. Cuando el diputado, tras haber sido expulsado del Salón de Sesiones, se negare a abandonarlo.

4. Cuando el diputado contraviniere lo dispuesto en el artículo 17 del Reglamento ( «Los diputados no podrán invocar o hacer uso de su condición de parlamentarios para el ejercicio de actividad mercantil, industrial o profesional»).

\section{B) Llamadas a la cuestión y al orden}

Al igual que en el anterior Reglamento (art. 82), en el artículo 103 del actual se recogen los motivos por los cuales los diputados y los oradores pueden ser llamados al orden. Sin embargo, este artículo 103 ha olvidado reseñar en un punto el caso de que se profieran palabras o vertieren conceptos ofensivos al decoro o dignidad de un Grupo Parlamentario (véase art. 71.3 RCD).

\section{C) El orden dentro del recinto parlamentario}

Poco decía el anterior Reglamento a este respecto, mientras que el actual le dedica tres preceptos (arts. 105, 106 y 107) dirigidos a velar por el mantenimiento del orden en el recinto del Congreso de los Diputados. Para ello, y en virtud de los poderes de policía que ejerce el presidente (otorgados por el artículo 72.3 del Reglamento), éste podrá adoptar cuantas medidas considere oportunas, poniendo incluso a disposición judicial a las personas que perturbaran dicho orden. Estas medidas pueden afectar tanto a diputados como al público que haya acudido a las sesiones públicas del Pleno y se sitúa en Tribunas.

\section{Pilar Mellado Prado}

NotA.-Mi agradecimiento a don Manuel Gonzalo, Letrado de las Cortes Generales, por la información facilitada para la elaboración de esta Crónica. 